\title{
Aggregation and survival of Neophilaenus albipennis (Hemiptera: Cercopidae) spittlebug nymphs
}

\author{
ROBERT BIEDERMANN \\ Landscape Ecology Group, Institute of Biology and Environmental Sciences, University of Oldenburg, 26111 Oldenburg, Germany; \\ e-mail: robert.biedermann@uni-oldenburg.de
}

Key words. Aggregation, Neophilaenus albipennis, nymphs, spittlebug, survival, vegetation structure

\begin{abstract}
The nymphs of spittlebugs (Hemiptera, Cercopidae) are xylem-feeders and live on herbs, grasses or woody plants within their self-produced spittle masses. Nymphs of the spittlebug Neophilaenus albipennis live aggregated in these spittle masses on their host plant Brachypodium pinnatum, a common grass in dry grassland. The objective of this study was to estimate nymphal mortality rates and to examine what role aggregation and vegetation structure play in the mortality of the nymphs. The aggregation and mortality were measured using two different methods, direct monitoring and caging of nymphs. The nymphs passively aggregated with up to 4 nymphs per spittle and aggregation decreased with instar. The aggregation of the nymphs resulted in a reduced mortality in all instars. Although it has already been argued that aggregation may be an advantage, this study is the first direct evidence (i.e. direct measurement of single individuals) for the benefit of aggregation to individual spittlebug nymphs. Despite a clumped distribution of $N$. albipennis nymphs in tall vegetation, nymphal mortality was not correlated with vegetation height.
\end{abstract}

\section{INTRODUCTION}

Aggregation of insects in the immature stage has been frequently documented in various taxonomic groups. The aggregation of sometimes large numbers of immatures may occur through passive aggregation due to clumped egg-laying (e.g. Atkinson \& Shorrocks, 1984) or active crowding (e.g. Bales \& Furniss, 1984), which may be driven by aggregation pheromones (Sauphanor \& Sureau, 1993). Particularly in phytophagous insects, aggregation may benefit the individual through enhanced exploitation of food resources (Tsubaki \& Shiotsu, 1982; Peterson, 1987), lower predation risk (Cappuccino, 1987; Turchin \& Kareiva, 1989; Lawrence, 1990), improved thermoregulation (Seymour, 1974) or faster development (Lawrence, 1990; Denno \& Benrey, 1997). On the other hand, aggregation may entail costs such as intra-specific competition (Faeth, 1990) or higher infection rates through, for instance, viruses (Hochberg, 1991). The balance of these advantages or disadvantages of aggregation will affect mortality of the immatures and thus may have a strong influence on the population dynamics of species.

The nymphs of spittlebugs (Hemiptera, Cercopidae) are xylem-feeders and live on herbs, grasses or woody plants within their self-produced spittle masses. The spittle consists of the excretion of surplus water originating from the large amount of ingested xylem sap, which may be enriched with mucopolysaccharides and proteins from the Malpighian tubules (Marshall, 1966; Mello et al., 1987). The spittle is thought to give shelter to the nymphs, protecting them from predation and providing a suitable microclimate (Whittaker, 1970). Within these spittle masses aggregation of the nymphs has been found in many species (e.g. Whittaker, 1965b; Mangan \& Wutz, 1983; Akiyama \& Matsumoto, 1986; Martin et al., 1995; Peck, 1998) and even aggregations of different species in one spittle mass have been documented (Halkka et al., 1977). Despite the ubiquity of aggregations in spittlebugs, there is little information on the role of the aggregation for nymphal survival. Is there reduced mortality in aggregated spittlebug nymphs? How does the aggregation come about?

To answer these questions, the nymphal biology of the spittlebug Neophilaenus albipennis was studied in detail. Nymphs of this species aggregate on the host plant $\mathrm{Bra}$ chypodium pinnatum. The objectives of this study were to (1) measure the mortality rates of aggregated and nonaggregated nymphs, (2) assess the effect of vegetation structure on nymphal mortality, and (3) shed light on the mechanism of aggregation of spittlebug nymphs. Nymphal mortality was measured by direct observations of individuals in the field and caging nymphs. The mortality rates were compared between aggregated and nonaggregated nymphs. If there is a benefit of aggregation, a lower mortality would be expected in aggregated nymphs. The distribution on the host plant and the instar composition of the nymphs within spittle masses were used to elucidate the mechanism of the aggregation, i.e. to answer the question whether there is an active or passive aggregation.

\section{MATERIALS AND METHODS}

\section{Study system}

The spittlebug Neophilaenus albipennis (Fabricius, 1798) (Hemiptera, Cercopidae) is univoltine and hibernates in the egg stage. The nymphs hatch in April and live in self-produced spittle masses. The species exhibits five instars. In the study area the first adults occurred in June and were found until September. The density of older nymphs was up to 5.0 nymphs per $0.25 \mathrm{~m}^{2}(\mathrm{n}=6$, S.D. $=4.3)$. The nymphs live on the stems of the grass Brachypodium pinnatum (L.) P.B., a clonal plant not building distinct tufts but its erect stems being relatively sepa- 


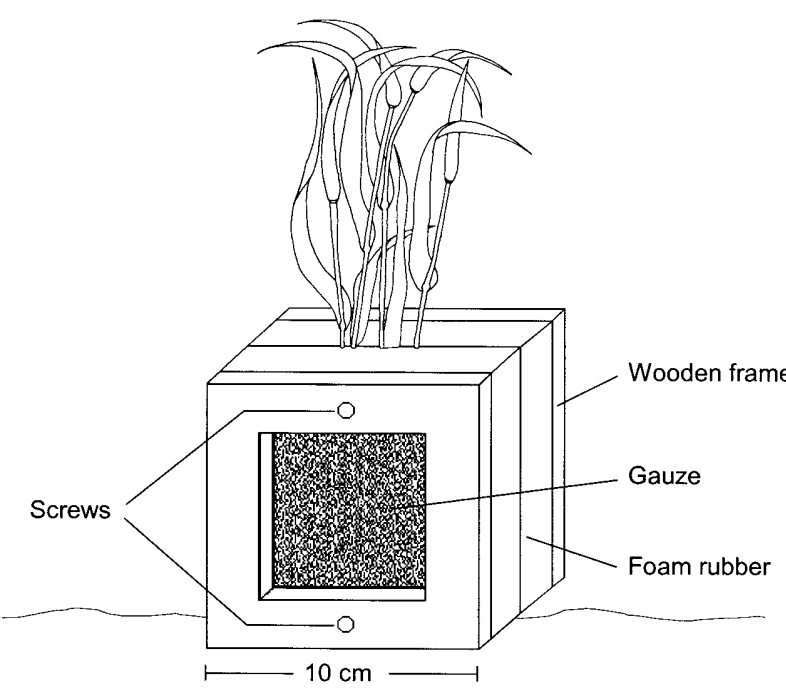

Fig. 1. Mini-cage used for measuring the mortality of the nymphs of Neophilaenus albipennis by exclusion of predators.

rated (see Fig. 1). In the study area B. pinnatum grows in dense and homogenous stands. In Central Europe $N$. albipennis occurs in dry grassland sites. This study was conducted in the porphyry landscape north of Halle in Sachsen-Anhalt, Germany. A description of the study area is given by Bliss et al. (1996). Within the study area 506 host plant patches were identified and mapped (Biedermann, 2000). Two large patches, Br2 (area: 390 $\left.\mathrm{m}^{2}\right)$ and $\operatorname{Br} 498\left(1293 \mathrm{~m}^{2}\right)$, were chosen for the detailed study of the nymphal aggregation and survival.

\section{Phenology, aggregation and distribution}

The instar composition during the development of the nymphs was measured using the quadrat sampling method. This method has been frequently used to quantify the density of spittlebug nymphs (e.g. Whittaker, 1965a; Martin et al., 1995; Whittaker \& Tribe, 1998). At each of the two patches, $\mathrm{Br} 2$ and $\mathrm{Br} 498$, spittle masses were examined in plots of $0.5 \times 0.5 \mathrm{~m}$. In the two patches on each sampling date six plots were chosen randomly. The nymphs were counted and their instar was determined using Vilbaste (1982). Additionally, some nymphs were reared to adults in the laboratory to confirm their species. Samples were taken every 3 to 7 days. For the measurement of aggregation, additional randomly chosen spittle masses were examined outside these plots $(n=124)$. The degree of aggregation was calculated for each instar as the proportion of nymphs that lived in nymphal aggregation (one to four nymphs).

The nymphs of $N$. albipennis live fairly sessile on their host plants. In patch $\mathrm{Br} 2$ the position above ground of the nymphs on their individual host plant stem (marked by labels, see below) was recorded during nymphal development. In order to characterise the locations where nymphs live, the height of the vegetation layer was documented by simply measuring the height of the surface of the dense and homogenous grass layer (predominated by the host plant $B$. pinnatum), peaks formed by single taller plants were disregarded. The vegetation height was measured both at locations where nymphs were found and at random samples within the patch.

\section{Mortality}

Two parallel methods were used to estimate nymphal mortality. (1) The patches $\mathrm{Br} 2$ and $\mathrm{Br} 498$ were searched for spittle masses of $N$. albipennis, nymphs were identified to instar, and the corresponding stem of the host plant was marked by a label $(\mathrm{n}=76$ ). The host plant $B$. pinnatum is not a tufted grass, thus single stems are distinct from each other and can be clearly relocated using the attached labels. The nymphs seldom moved to other individual host plants. Frequently the exuviae of preceding moultings could be found in the spittle masses. Thus it was possible to relocate the spittle masses individually. The degree of aggregation with other nymphs, the development and the mortality were recorded for each nymph over time. The status (dead or alive) of the nymphs was recorded every 2 to 4 days from early May to late June 1995. From these data the mortality rate of each instar was calculated. (2) Mini-cages, 15 in $\mathrm{Br} 2$ and 5 in $\mathrm{Br} 498$, were attached to the host plants. Those cages have been successfully used in the study of the development of spittlebug nymphs (Halkka et al., 1967; Whittaker, 1968, 1971; Halkka \& Mikkola, 1977). The cages prevent the escape of the nymphs and the access of predators. The cages used in this study consisted of two frames of foam rubber covered by two wooden frames that are held together with two screws (Fig. 1). The wooden frames were covered by gauze. Resting on the ground, the cages were attached to host plants with one spittle mass containing up to three nymphs. The stems were clamped between the two frames of foam rubber (see Fig. 1), so that growth and photosynthesis of most parts of the host plants would be little affected. The development and mortality of the nymphs was measured every 5 to 10 days. Additionally the cages were used to determine the mortality of nymphs of instar $\mathrm{V}$, which is not possible with the technique of individual marking of the stems where the nymphs live. The moulting adults live outside the spittle and would disappear from the marked stems.

In both approaches, a spatula was used to lift the spittle from the nymphs in order to follow the fate of the nymphs in the spittle masses. After the examination the nymphs were manually covered with spittle again.

At the locations of the nymphs the vegetation height was measured. A logistic regression analysis (using SPSS 10.0, SPSS Inc., Chicago, Illinois) was performed in order to test the influence of vegetation height on the survival of the nymphs. Due to continued growth of the vegetation during nymphal development, the values of vegetation height were standardised within each instar and the samples were pooled.

\section{RESULTS}

\section{Phenology}

In patch $\mathrm{Br} 2$, after hibernation of the eggs, first instars were detected at the end of April to the beginning of May (Fig. 2a). Instars II to IV occurred in May, while instar V peaked early June. In patch Br498, the nymphal stages were delayed by about 10 days compared to $\mathrm{Br} 2$ (Fig. $2 b$ ). The duration of nymphal development, however, was not prolonged (Fig. 2). In both patches the development from instar I to the adult took 6 to 7 weeks. No obvious differences in stadia were detected; each took 8 to 10 days.

\section{Distribution}

The nymphs of $N$. albipennis were found at the base of the stems of their host plant. The mean position of nymphs at instar I was $1.5 \mathrm{~cm}$ above ground (Table 1). With successive instars the position on the stem increased up until instar $\mathrm{V}$ with a mean of $4.8 \mathrm{~cm}$. The variation in the position at the stem also increased with instar. Mean stem length increased from 15.9 to $29.4 \mathrm{~cm}$ over the period of nymphal development. In spite of this consider- 

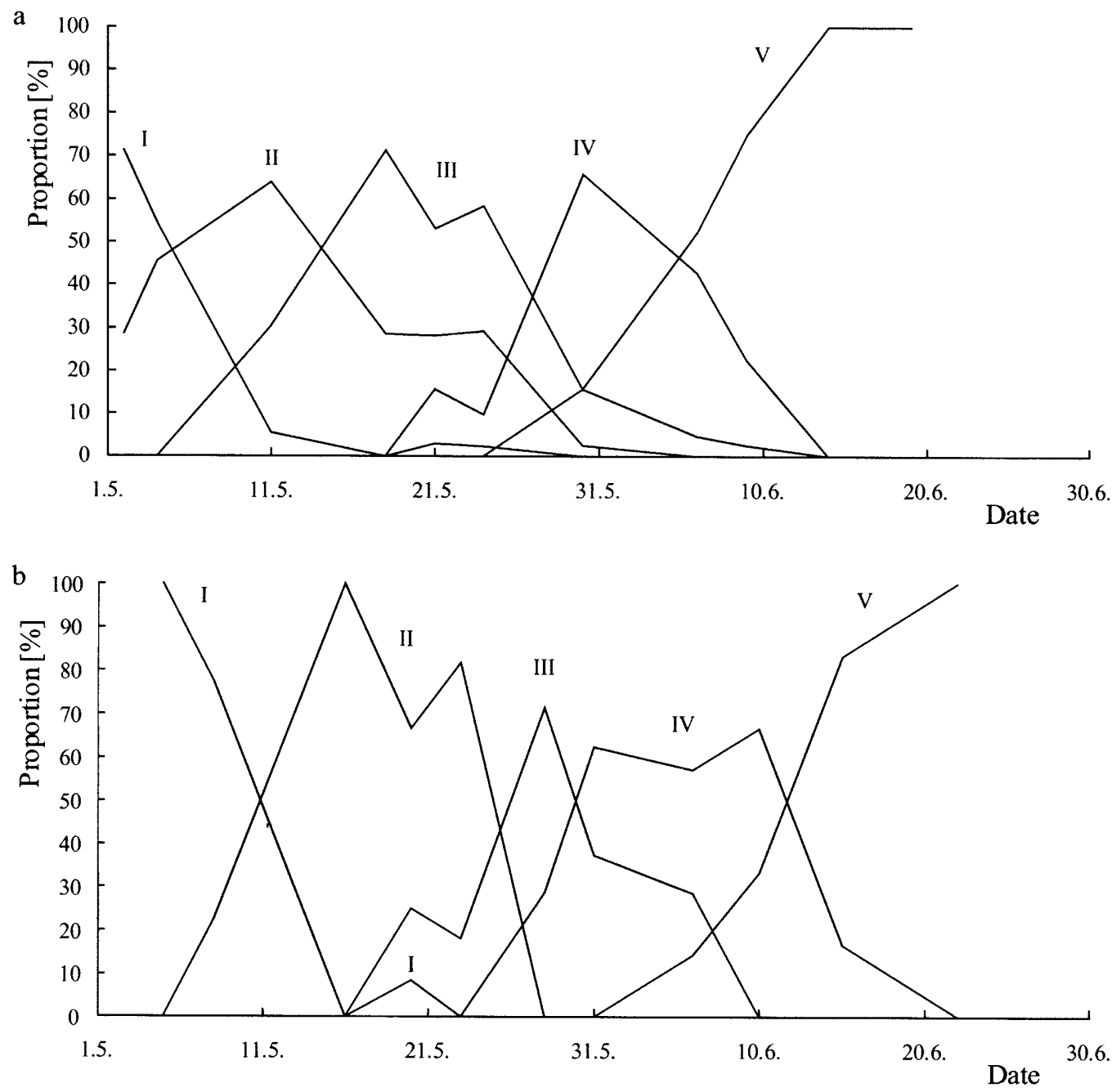

Fig. 2. Phenology of the instars (I-V) of Neophilaenus albipennis in (a) $\mathrm{Br} 2$ and (b) Br498.

able growth of the host plant, nymphs remained within a fairly restricted zone at the base of the vegetation layer.

After an examination of 386 spittle masses, more than one spittle mass per plant stem was found on only one occasion (two nymphs at instar IV). All other nymphs lived aggregated or singly in one spittle mass per stem. The nymphs were regularly found in tall and dense vegetation. The analysis of the vegetation structure showed that vegetation was taller at locations where nymphs were found, in contrast to random samples in the patches (Table 2).

TABle 1. Position above ground of the nymphs of Neophilaenus albipennis at the host plant stem and stem length (mean and standard deviation).

\begin{tabular}{|c|c|c|c|}
\hline Instar & \multicolumn{2}{|c|}{ Height above ground $(\mathrm{cm})$} & Stem length $(\mathrm{cm})$ \\
\hline I & $1.5 \pm 0.7$ & $(n=18)$ & $15.9 \pm 5.8$ \\
\hline II & $1.9 \pm 0.9$ & $(\mathrm{n}=97)$ & $18.7 \pm 6.5$ \\
\hline III & $2.4 \pm 1.1$ & $(\mathrm{n}=67)$ & $20.3 \pm 6.7$ \\
\hline IV & $3.3 \pm 1.5$ & $(\mathrm{n}=28)$ & $26.0 \pm 9.0$ \\
\hline V & $4.8 \pm 3.2$ & $(n=47)$ & $29.4 \pm 5.9$ \\
\hline
\end{tabular}

\section{Aggregation}

The nymphs of $N$. albipennis were aggregated in the spittle masses; up to 4 nymphs per spittle mass were discovered (Fig. 3). The highest aggregation occurred in instar I where $63.4 \%$ lived in aggregations in Br498, $44.4 \%$ in $\mathrm{Br} 2$. In Br498 19.5\% of instar I lived twosome in the spittle, $39.0 \%$ threesome and $4.9 \%$ foursome. In $\mathrm{Br} 2$ instar I did not aggregate beyond twosomes. Patch differences were less pronounced for later instars. The degree of aggregation generally decreased with successive instars. The degree of aggregation declined from instar I to instar III and varied from 9.0 and $14.8 \%$ for instar IV and V. Instar IV and V were never found aggregated beyond threesomes.

In addition to $N$. albipennis, nymphs of the spittlebug Philaenus spumarius (Linneus, 1758) were recorded. In 4 out of 368 spittle masses examined (1.1\%), the nymphs of both species were found in the same spittle mass. Beyond instar III, however, no nymphs of $P$. spumarius were found together with $N$. albipennis.

\section{Mortality}

The mortality of the nymphs decreased from instar I to instar IV (Table 3). The highest mortality rate was found 

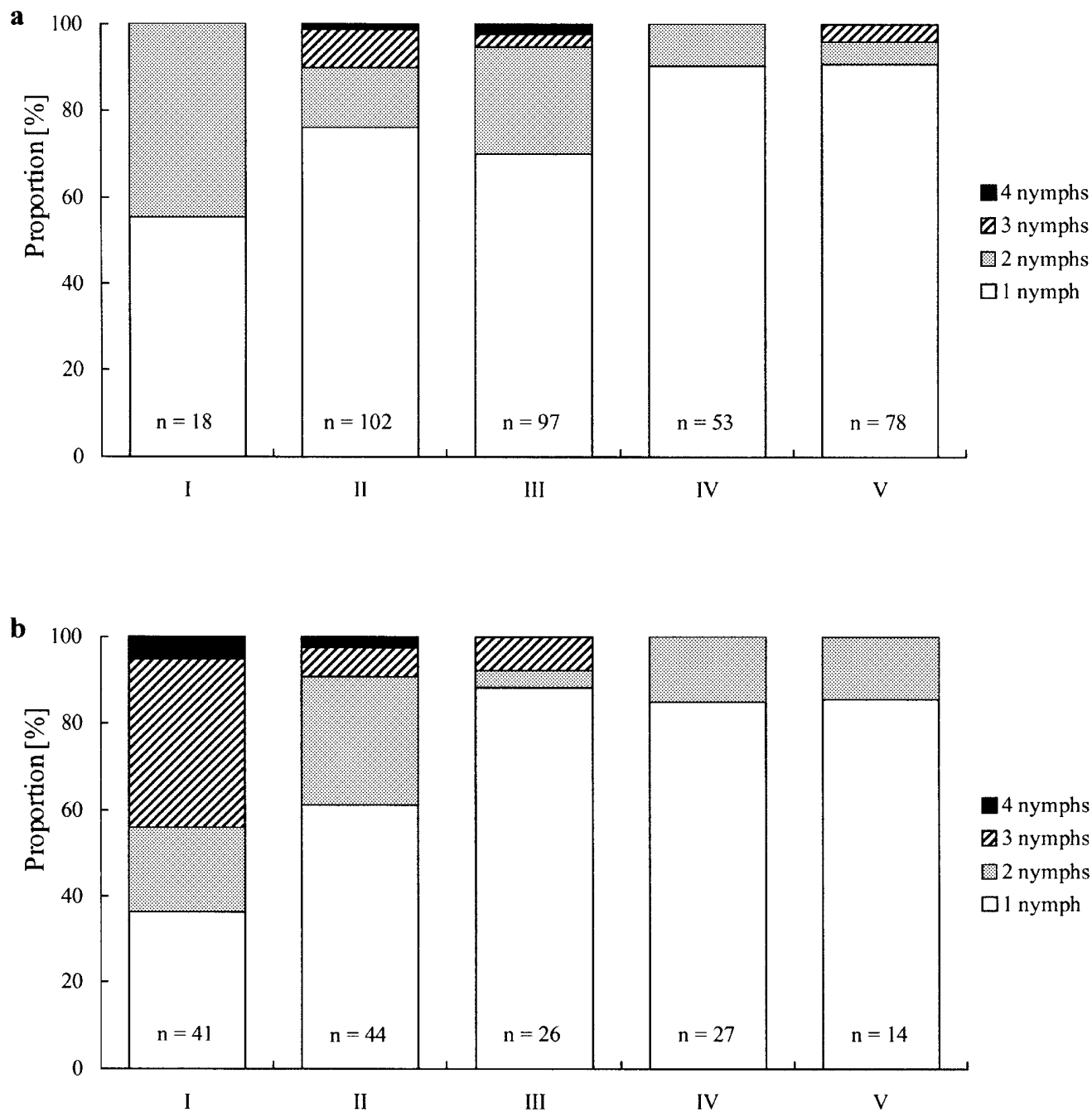

Fig. 3. Aggregation of the nymphs of Neophilaenus albipennis in (a) $\mathrm{Br} 2$ and (b) $\mathrm{Br} 498$.

in instar $\mathrm{I}, 0.833$ in $\mathrm{Br} 2$ and 0.500 in $\mathrm{Br} 498$. The mortality of instar IV was 0.311 and 0.462 in $\mathrm{Br} 2$ and $\mathrm{Br} 498$, respectively. The overall survival rate from instar I to instar V (Fig. 4) was similar in both patches, 0.043 in $\mathrm{Br} 2$ and 0.085 in Br498. The mortality from instar $\mathrm{V}$ to the adults was only measured using the cages and was 0.167 in both patches. Thus the total survival rate from instar I to the adults was estimated at 0.036 in $\mathrm{Br} 2$ and 0.070 in Br498.

A significant difference in the mortality was found between aggregated and non-aggregated nymphs $\left(\mathrm{Chi}^{2}=\right.$ $4.39, \mathrm{p}=0.036, \mathrm{n}=245$, all samples pooled). In both patches, $\mathrm{Br} 2$ and $\mathrm{Br} 498$, the mortality was 0.090 to 0.361 lower (mean 0.205) in aggregated nymphs (Table 4). The difference between aggregated and non-aggregated nymphs was apparent in all instars I to IV and was fairly stable through the development of the nymphs. The mor- tality was not influenced by vegetation height at the location of the nymphs. In a logistic regression analysis the vegetation height yielded no significant explanation of survival of the nymphs $\left(\mathrm{Chi}^{2}=1.962, \mathrm{p}=0.161, \mathrm{n}=221\right.$, all samples pooled).

As in free-living nymphs, nymphal mortality in the cages decreased with instar (Table 3 ). The mortality in instar I was 0.500 in $\mathrm{Br} 2$ and 0.583 in $\mathrm{Br} 498$ whereas in instar IV almost all nymphs survived to the succeeding instar. With the exception of instar III in $\mathrm{Br} 2$ and instar I in Br498, nymphal mortality in the cages was reduced. However, the total survival rate from instar I to instar IV was higher in nymphs in the cages (Fig. 4), 0.140 in Br2 and 0.176 in $\mathrm{Br} 498$. Overall, however, there was no significant difference in survival between nymphs in the cages and free-living nymphs $\left(\mathrm{Chi}^{2}=2.693, \mathrm{p}=0.101, \mathrm{n}\right.$ $=322$, all samples pooled).

TABLE 2. Comparison of the vegetation height at nymph locations and random locations using t-test.

\begin{tabular}{|c|c|c|c|c|c|c|c|c|}
\hline \multirow[t]{2}{*}{ Patch } & \multicolumn{3}{|l|}{ Nymphs } & \multicolumn{3}{|c|}{ Random } & \multicolumn{2}{|c|}{ t-test } \\
\hline & Vegetation height $[\mathrm{cm}]$ & S.D. & $n$ & Vegetation height $[\mathrm{cm}]$ & S.D. & $n$ & $\mathrm{t}$ & $\mathrm{p}$ \\
\hline $\mathrm{Br} 2$ & 21.7 & 6.7 & 51 & 14.6 & 5.4 & 19 & -4.068 & $<0.001$ \\
\hline $\mathrm{Br} 498$ & 17.9 & 6.6 & 18 & 14.8 & 5.2 & 20 & -1.640 & 0.110 \\
\hline
\end{tabular}




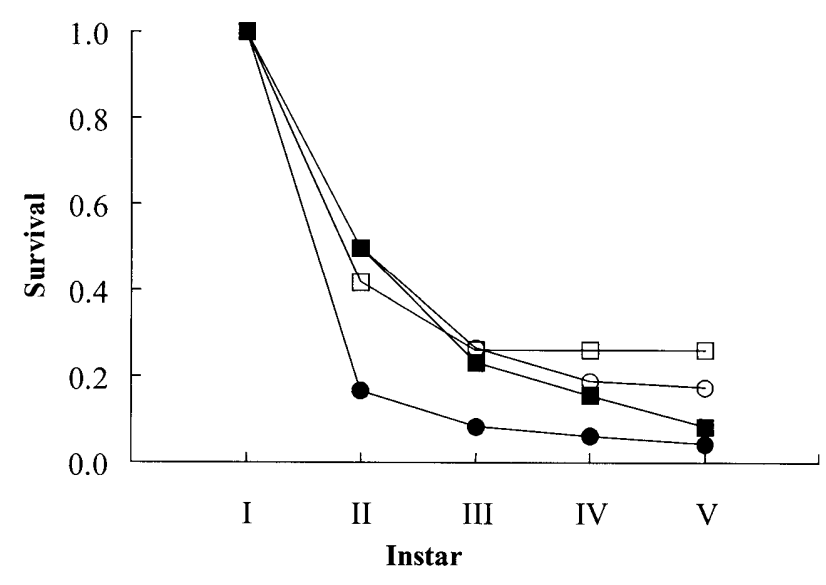

Fig. 4. Survival rate of the nymphs of Neophilaenus albipennis in $\mathrm{Br} 2$ (circles) and $\mathrm{Br} 498$ (squares) determined with two methods: Individual marking (solid symbols) and caging with exclusion of predators (open symbols).

\section{DISCUSSION}

\section{Survival of the nymphs}

The nymphal mortality rates decreased with instar and were similar to mortality rates estimated in other Neophilaenus species (Whittaker, 1965b). No substantial difference in total survival rate was found between the two patches $\mathrm{Br} 2$ and $\mathrm{Br} 498$, however, the phenology of the nymphs differed. Patch $\mathrm{Br} 2$ is a south facing slope with an inclination of 2 degrees, whereas the patch Br498 is north-east facing with an inclination of 25 degrees. The date of occurrence of the instars was apparently delayed in the north facing slope.

The cages used to determine nymphal mortality excluded predators. A comparison with mortality rates obtained from free-living nymphs might yield an estimate of predation rate. However, the cages could affect microclimate or host plant quality (e.g. Crafts-Brandner \& Chu, 1999) and thus mortality rates of the caged nymphs. A more controlled study would be necessary to quantify possible cage-effects. Nevertheless, the results indicate that nymphal mortality of $N$. albipennis may only be little affected by predation, a conclusion concordant with existing studies on other spittlebugs. Although in some species predation by invertebrates and birds has been recorded by indirect data of prey records (Harper \& Whittaker, 1976; Callan, 1980; Kristin, 1995), in all quantitative studies very low rates of predation have been found (Whittaker, 1965b, 1970, 1971; Halkka \& Kohila, 1976).

Despite the observation of a clumped occurrence of nymphs in tall vegetation, the analysis of nymphal mortality in relation to vegetation height yielded no indication
TABLE 3. Stage specific mortality $\left(\mathrm{q}_{\mathrm{x}}\right)$ of the nymphs of Neophilaenus albipennis determined with two methods: individual marking (IM) and caging (CA).

\begin{tabular}{lcccc}
\hline Instar & \multicolumn{2}{c}{ Br2 mortality $\left(\mathrm{q}_{\mathrm{x}}\right)$} & \multicolumn{2}{c}{ Br498 mortality $\left(\mathrm{q}_{\mathrm{x}}\right)$} \\
\cline { 2 - 5 } & $\mathrm{IM}$ & $\mathrm{CA}$ & $\mathrm{IM}$ & $\mathrm{CA}$ \\
\hline I & 0.833 & 0.500 & 0.500 & 0.538 \\
& $(\mathrm{n}=12)$ & $(\mathrm{n}=2)$ & $(\mathrm{n}=18)$ & $(\mathrm{n}=12)$ \\
II & 0.490 & 0.467 & 0.538 & 0.375 \\
& $(\mathrm{n}=51)$ & $(\mathrm{n}=15)$ & $(\mathrm{n}=26)$ & $(\mathrm{n}=8)$ \\
III & 0.261 & 0.294 & 0.320 & 0.000 \\
& $(\mathrm{n}=46)$ & $(\mathrm{n}=17)$ & $(\mathrm{n}=25)$ & $(\mathrm{n}=6)$ \\
IV & 0.311 & 0.083 & 0.462 & 0.000 \\
& $(\mathrm{n}=45)$ & $(\mathrm{n}=12)$ & $(\mathrm{n}=22)$ & $(\mathrm{n}=5)$ \\
V & & 0.167 & & 0.167 \\
& \multicolumn{5}{c}{$(\mathrm{n}=24)$} \\
\hline
\end{tabular}

of enhanced survival. Female spittlebugs of the genus Neophilaenus deposit their eggs in clumps on their host plants (Braasch, 1960; Whittaker, 1965b). The observed concentration of nymphs of $N$. albipennis in tall vegetation may be due to preferences of the females when laying eggs. However, differences in hibernating egg mortality between tall and low vegetation might also be responsible for the observed accumulation.

\section{Formation of aggregations}

Nymphs of $N$. albipennis on the same host plant live aggregated in their spittle masses. The degree of aggregation (maximum: 1.7 nymphs per spittle) was comparable to other spittlebugs (e.g. Whittaker (1965b) reported in Neophilaenus lineatus maximum 1.5 nymphs per spittle, in Neophilaenus exclamationis maximum 1.2 nymphs per spittle). Although spittle masses of $N$. albipennis were usually limited to the basal $5 \mathrm{~cm}$ of the stem and there is a high degree of overlap among instars, height on the plant increases significantly with instar. The preference of distinct parts of the host plant has also been shown by McEvoy (1986) in the two spittlebugs Philaenus spumarius and Lepyronia quadrangularis. The diameter of the $N$. albipennis spittle masses is much less than the potential distance between recorded feedings sites on the host plants. Thus, the spittle masses of several nymphs on one host plant should not necessarily be confluent. That all nymphs on that plant live aggregated in one spittle mass is evidence for strong aggregation. How does this aggregation come about? It is known that female spittlebugs of the genus Neophilaenus deposit their eggs in clumps in rifts like axils of their host plants (Braasch, 1960; Whittaker, 1965b). So it seems likely that the aggregation of the nymphs at the first instar may be due

TABLE 4. Stage specific mortality $\left(\mathrm{q}_{\mathrm{x}}\right)$ of non-aggregated and aggregated nymphs of Neophilaenus albipennis.

\begin{tabular}{lcccc}
\hline Instar & \multicolumn{2}{c}{ Br2 mortality $\left(\mathrm{q}_{\mathrm{x}}\right)$} & \multicolumn{2}{c}{ Br498 mortality $\left(\mathrm{q}_{\mathrm{x}}\right)$} \\
\cline { 2 - 5 } & Non-aggregated & Aggregated & Non-aggregated & Aggregated \\
\hline I & $0.889(\mathrm{n}=9)$ & $0.667(\mathrm{n}=3)$ & $0.667(\mathrm{n}=6)$ & $0.417(\mathrm{n}=12)$ \\
II & $0.528(\mathrm{n}=36)$ & $0.400(\mathrm{n}=15)$ & $0.571(\mathrm{n}=14)$ & $0.333(\mathrm{n}=12)$ \\
III & $0.290(\mathrm{n}=31)$ & $0.200(\mathrm{n}=15)$ & $0.350(\mathrm{n}=20)$ & $0.200(\mathrm{n}=5)$ \\
IV & $0.342(\mathrm{n}=38)$ & $0.143(\mathrm{n}=7)$ & $0.611(\mathrm{n}=18)$ & $0.250(\mathrm{n}=4)$ \\
\hline
\end{tabular}


to clumped egg-laying rather than to active crowding over larger distances.

\section{Causes of reduced mortality of aggregated nymphs}

The nymphs of $N$. albipennis live aggregated in spittle masses and the degree of aggregation declines with increasing development as documented in most studies on spittlebugs (Oomen, 1975; Bales \& Furniss, 1984; Akiyama \& Matsumoto, 1986; but see Whittaker, 1965b). The aggregation of the nymphs resulted in a reduced mortality during nymphal development. Although it has been argued that aggregation may be an advantage (e.g. Matsumoto, 1990), this study is the first direct evidence for the benefit of aggregation to individual spittlebug nymphs.

In phytophagous insects it is believed that one major benefit of aggregation is a reduced predation risk (e.g. Cappuccino, 1987; Turchin \& Kareiva, 1989; Lawrence, 1990). However, as the predation pressure on spittlebug nymphs generally is rather low (see above), it is unlikely that protection from predation is a major cause of the reduced mortality rates of aggregated nymphs. Thus, other reasons should explain the reduced mortality of aggregated spittlebug nymphs. One, as known from other insects (e.g. Tsubaki \& Shiotsu, 1982), aggregations may have advantages for the exploitation of food resources. In spittlebugs, there may be a nutrient sink in the vicinity of other nymphs. Two, after destruction of the spittle (such as from heavy rainfall) aggregated nymphs may be able to build up the protecting spittle more quickly than single nymphs. Three, each nymph in an aggregation could reduce its contribution to the production of spittle and could thereby save energy and resources (Bales \& Furniss, 1984).

The aggregation of Aphrophora spittlebug nymphs has been shown to increase with density (Matsumoto, 1990; Biedermann, unpubl.). However, there may be a trade-off between the benefit of aggregation and increased intraspecific competition between nymphs. At low densities, the aggregation may be beneficial. The mortality is reduced in aggregated nymphs, as shown in this study. At higher densities the aggregation (with up to 100 nymphs in some species) may be limited by feeding site availability so that intra-specific competition may increase and override the beneficial effect of aggregation. In fact, Matsumoto (1990) found the lowest mortality of the nymphs of Aphrophora flavipes at medium densities and thus medium aggregation. In $N$. albipennis the aggregation of up to 4 nymphs resulted in higher survival rate whereas it remains untested what happens at higher densities and aggregations.

A second possibility of a disadvantage of aggregation concerns the physiology of the host plant. The aggregation of spittlebug nymphs may be an advantage under normal conditions, where xylem is not limited. However, during longer periods of draught, the content or flow of xylem sap may be deteriorated. As a consequence, competition between nymphs in one spittle may occur and may result in the survival of the fittest nymph in the spittle.
ACKNOWLEDGEMENTS. I thank three anonymous referees for helpful comments and suggestions. This work was supported by the German Ministry of Education and Research (FKZ 0339524 A).

\section{REFERENCES}

Akryama M. \& Matsumoto K. 1986: Biology of the pine spittlebug, Aphrophora flavipes (Homoptera: Cercopidae) in the nymphal stage. Jap. J. Appl. Entomol. Zool. 30: 136-141.

AtKInson W.D. \& Shorrocks B. 1984: Aggregation of larval Diptera over discrete and ephemeral breeding sites: the implications for coexistence. Am. Nat. 124: 336-351.

BALES F.M. \& FurnISS M.M. 1984: Bionomics of the cone spittlebug, Aphrophora canadensis (Homoptera: Cercopidae) on mugo pine in Idaho. Great Basin Nat. 44: 338-348.

BiedermanN R. 2000: Metapopulation dynamics of the froghopper Neophilaenus albipennis (Fabricius, 1798) (Homoptera: Cercopidae) - what is the minimum viable metapopulation size? J. Ins. Cons. 4: 99-107.

Bliss P., Kuhn W., Schöpke H., Settele J. \& Wallaschek M. 1996: The hilly landscape of Halle - main study area of the FIFB. In: Settele J., Margules C., Poschlod P. \& Henle K. (eds): Species Survival in Fragmented Landscapes. Kluwer Academic Publishers, Dordrecht, pp. 161-168.

BraAsch H. 1960: Über die Eihüllsekrete einheimischer Cercopiden (Homoptera, Cicadina). Z. Morph. Ökol. Tiere 49: 184-262.

CALlan E.M. 1980: Nesting behavior and prey of Argogorytes Asmead (Hymenoptera: Specidae). J. Washington Acad. Sci. 70: $160-165$.

CAPPuCCINO N. 1987: Comparative population dynamics of two goldenrod aphids: spatial patterns and temporal constancy. Ecology 68: 1634-1646.

Crafts-Brandner S.J. \& Chu C.-C. 1999: Insect clip cages rapidly alter photosynthetic traits of leaves. Crop Sci. 39: 1896-1899.

Denno R.F. \& BenRey B. 1997: Aggregation facilitates larval growth in the neotropical nymphalid butterfly Chlosyne janais. Ecol. Entomol. 22: 133-141.

FAETH S.H. 1990: Aggregation of leafminer, Cameria sp. nov. (Davis): consequences and causes. J. Anim. Ecol. 59: $569-586$.

Halkka O., Raatikainen M., Vasarainen A. \& Heinonen L. 1967: Ecology and ecological genetics of Philaenus spumarius (L.) (Homoptera). Ann. Zool. Fenn. 4: 1-18.

HALKKa O. \& Kohlla T. 1976: Persistence of visual polymorphism, despite a low rate of predation, in Philaenus spumarius (L.) (Homoptera: Aphrophoridae). Ann. Zool. Fenn. 13: $185-188$.

HalkKa O. \& Mikkola E. 1977: The selection regime of Philaenus spumarius L. In: Christiansen F.B. \& Fenchel T. (eds): Measuring Selection in Natural Populations. Lecture Notes in Biomathematics, 19. Springer, Heidelberg, pp. 445-463.

Halkka O., RaAtikainen M., Halkka L. \& RaAtikainen T. 1977: Coexistence of four species of spittle-producing Homoptera. Ann. Zool. Fenn. 14: 228-231.

Harper G. \& WhitTAKer J.B. 1976: The role of natural enemies in the colour polymorphism of Philaenus spumarius (L.). $J$. Anim. Ecol. 45: 91-104.

HochBerg M.E. 1991: Viruses as costs to gregarious feeding behaviour in the Lepidoptera. Oikos 61: 291-296.

KRISTIN A. 1995: The diet and foraging ecology of the penduline tit (Remiz pendulinus). Folia Zool. 44: 23-29.

LAWRENCE W.S. 1990: The effects of group size and host species on development and survivorship of a gregarious caterpillar 
Halisidota caryae (Lepidoptera: Arctiidae). Ecol. Entomol. 15: $53-62$.

MANGAN R.L. \& WuTZ A. 1983: Aggregation patterns of meadow spittlebugs, Philaenus spumarius L. (Homoptera: Cercopidae), on old-field alfalfa plants. Environ. Entomol. 12: 151-157.

Marshall A.T. 1966: Spittle-production and tube-building by cercopid larvae (Homoptera). - IV. Mucopolysaccharide associated with spittle production. J. Insect Physiol. 12: 635-644.

Martin R.M., Cox J.R., Alston D.G. \& Ibarra F. 1995: Spittlebug (Homoptera: Cercopidae) life cycle on buffelgrass in Northwestern Mexico. Ann. Entomol. Soc. Am. 88: 471-478.

Matsumoto K. 1990: Effects of density on the survival and development of nymphs in the pine spittlebug, Aphrophora flavipes (Homoptera: Cercopidae). Experiments in an outdoor cage. Appl. Entomol. Zool. 25: 339-346.

McEvor P.B. 1986: Niche partitioning in spittlebugs (Homoptera: Cercopidae) sharing shelters on host plants. Ecology 67 : 465-478.

Mello M.L.S., Pimentel E.R., Yamada A.T. \& Storopoli-Neto A. 1987: Composition and structure of the froth of the spittlebug, Deois sp. Insect Biochem. 17: 493-502.

OOMEN P.A. 1975: A population study of the spittle bugs Aeneolamia occidentalis (Walk.) and Prosapia simulans (Walk.) (Homoptera: Cercopidae) in Mexican Pangola pastures. Z. Angew. Entomol. 79: 225-238.

PeCK D.C. 1998: Natural history of the spittlebug Prosapia nr. bicincta (Homoptera: Cercopidae) in association with dairy pastures of Costa Rica. Ann. Entomol. Soc. Am. 91: 435-444.

Peterson S.C. 1987: Communication of leaf suitability by gregarious eastern tent caterpillars (Malacosoma americanum). Ecol. Entomol. 12: 283-289.

SEYMour R.S. 1974: Convective and evaporative cooling in sawfly larvae. J. Insect Physiol. 20: 2447-2457.
Sauphanor B. \& Sureau F. 1993: Aggregation behaviour and interspecific relationships in Dermaptera. Oecologia 96: 360-364.

TsubaKi Y. \& ShIOTSU Y. 1982: Group feeding as a strategy for exploiting food resources in the burnet moth Pryeria sinica. Oecologia 55: 12-20.

Turchin P. \& Karenva P. 1989: Aggregation in Aphis varians: an effective strategy for reducing predation risk. Ecology 70: $1008-1016$.

Vilbaste J. 1982: Preliminary key for the identification of the nymphs of North European Homoptera Cicadinea. II. Cicadelloidea. Ann. Zool. Fenn. 19: 1-20.

WhitTAKer J.B. 1965a: The biology of Neophilaenus lineatus (L.) and N. exclamationis (Thunberg) (Homoptera: Cercopidae) on Pennine moorland. Proc. R. Entomol. Soc. A 40: $51-60$.

WhitTAKeR J.B. 1965b: The distribution and population dynamics of Neophilaenus lineatus (L.) and N. exclamationis (Thun.) (Homoptera: Cercopidae) on Pennine moorland. $J$. Anim. Ecol. 34: 277-297.

Whittaker J.B. 1968: Polymorphism of Philaenus spumarius (L.) (Homoptera, Cercopidae) in England. J. Anim. Ecol. 37: 99-111.

WhitTaker J.B. 1970: Cercopid spittle as a microhabitat. Oikos 21: $59-64$.

WhitTaKer J.B. 1971: Population changes in Neophilaenus lineatus (L.) (Homoptera: Cercopidae) in different parts of its range. J. Anim. Ecol. 40: 425-443.

Whittaker J.B. \& Tribe N.P. 1998: Predicting numbers of an insect (Neophilaenus lineatus: Homoptera) in a changing climate. J. Anim. Ecol. 67: 987-991.

Received October 18, 2002; revised May 19, 2003; accepted May 29, 2003 